\title{
Diagnosis of Simulated External Root Resorption Using Conventional Intraoral Film Radiography, CCD, PSP, and CBCT: A Comparison Study
}

\author{
Abbas Shokri ${ }^{1}$, Hamed Mortazavi ${ }^{2}$, Fatemeh Salemi ${ }^{1}$, Adineh Javadian ${ }^{1}$, Hamidreza Bakhtiari ${ }^{1}$, \\ Hooman Matlabi ${ }^{3}$
}

Background: Diagnosis of external root resorption (ERR) cavities may be challenging, especially when no clinical signs are seen. Therefore, the aim of this study was to compare the efficacy of conventional intraoral film radiography, charge-coupled device (CCD) detector, photostimulable phosphor plate (PSP) detector, and cone beam computed tomography (CBCT) for the detection of ERR.

Methods: The study sample comprised 54 maxillary first premolars. Cavities were created by using a low-speed handpiece with round diamond burs of $1 \mathrm{~mm}$ in diameter. Digital and conventional radiographs were taken from each tooth. Three observers examined all images for the presence of resorption cavities. Data were statistically analyzed with the $\chi^{2}$ test. The reliability and degrees of agreement were also determined by the mean of Cohen's Kappa analysis.

Results: The differences between the imaging methods in correct

At a Glance Commentary

Scientific background of the subject

Lesions less than $0.3 \mathrm{~mm}$ in depth and $0.6 \mathrm{~mm}$ in diameter are not detected by conventional periapical radiography. For these reasons, new diagnostic radiographic methods such as three-dimensional (3D) images can have an important role in dental practice.

\section{What this study adds to the field}

Dental practitioners should consider that while CBCT is a new technology in radiographic assessment, it was only applicable for detection of cavities located in the apical one-third of the root. detection of root resorption for all sizes were not significant. For locations of root resorption, significant differences were found between CBCT and other methods in the apical regions.

Conclusions: CBCT was only useful for detection of cavities located in the apical one-third of the root, compared to other digital or conventional methods.

(Biomed J 2013;36:18-22)

Key words: conventional radiography, diagnosis, digital radiography, root resorption

E xternal root resorption (ERR) is a common condition associated with either a physiologic or pathologic dissolution of mineralized tissues like dentin, cementum, and/or alveolar bone, primarily by clastic cells. ${ }^{[1,2]}$ The process of root resorption may be inconsequential, lasting for about 3 weeks. However, with continual stimulation (e.g., infection or pressure), the clastic cells will continue to resorb the unprotected surface of root, which may result in extensive defect to the tooth. ${ }^{[3,4]}$ Clinical and radiological examinations were used for diagnosis of the resorptive process. ${ }^{[2]}$ Root resorption usually does not present a clinical sign or symptom. Therefore, the diagnosis is mainly based on radiographic examination. ${ }^{[5,6]}$ At present, conventional intraoral film radiography (F), photostimulable phosphor (PSP) plate, and charge-coupled device (CCD) chips are the most commonly used radiological methods for the diag-

From the ${ }^{1}$ Department of Oral and Maxillofacial Radiology, Dental School, Hamadan University of Medical Sciences, Hamadan, Iran, ${ }^{2}$ Department of Oral Medicine, Dental School, Shahid Beheshti University of Medical Sciences, Tehran, Iran, ${ }^{3}$ Emergency Unit, Eliad Clinic, Tehran, Iran

Received: Nov. 21, 2011; Accepted: Mar. 21, 2012

Correspondence to: Dr. Hamed Mortazavi, Department of Oral Medicine, Dental School, Shahid Beheshti University of Medical Sciences, Tehran, Iran. Chamran Highway, Daneshjoo Blvd, Post code 1983969411, Tehran, Iran. Tel: 98-9155147386, Fax: 98-2122403194;

E-mail: mortazavi57@yahoo.com

DOI: $10.4103 / 2319-4170.107156$ 
nosis of ERR. Andreasen et al and Goldberg et al, reported that those lesions less than $0.3 \mathrm{~mm}$ in depth and $0.6 \mathrm{~mm}$ in diameter are not detected by conventional periapical radiography. ${ }^{[7,8]}$ For these reasons, new diagnostic radiographic methods such as three-dimensional (3D) images can have an important role in dental practice. Cone beam computed tomography (CBCT) has been designed to produce 3D image of dental structures and maxillofacial skeleton. ${ }^{[3,9]}$ The main advantages of CBCT include reduction in radiation exposure, rapid scan time, and fewer image artifacts. ${ }^{[10]}$ However, the diagnostic ability of CBCT in ERR has not been sufficiently studied. ${ }^{[9]}$

The aim of this study was to compare the accuracy of conventional intraoral film radiography (Kodak Insight), CCD detector (Sopro Imaging), PSP detector (Soredex), and CBCT (Newtom 3G) for the diagnosis of simulated ERR cavities.

\section{METHODS}

Sixty maxillary first premolars were obtained from the tooth bank of Endodontic Department of Hamadan Dental School. Teeth with root canal filling, root resorption, cracking, or fracture were excluded. After visual and radiologic evaluation, 54 intact teeth were selected. All root portions were divided into three parts: Cervical, middle, and apical.

To simulate the ERR, all tooth crowns were placed in plaster bases and then cavities were created by using a low-speed handpiece with round diamond burs of $1 \mathrm{~mm}$ in diameter and water as a coolant.

The number and the location of the cavities in each root were determined randomly. The number of cavities varied from 0 to 3 , and the location of them was considered in cervical, middle, or apical thirds either on mesial or distal surfaces.

Cavities were $1 \mathrm{~mm}$ in diameter and $0.5 \mathrm{~mm}$ (small), $1 \mathrm{~mm}$ (medium), and $1.5 \mathrm{~mm}$ (large) in depth. In this study, six teeth did not have any simulated ERR. All teeth were randomly numbered from 1 to 54 . Also, the number, location, and size of all cavities were listed and saved for each tooth [Table 1].

Teeth were removed carefully from plaster and separately repositioned in alveolar socket of a cadaver skull.

This skull was borrowed with ethical approval from Department of Anthropology. Soft tissue simulation was conducted by covering the bone with wax plates. Conventional and digital intraoral images (CCD, PSP) of the specimens were taken. Digital detectors and conventional radiographic films were held in place with holders.

After intraoral imaging, the skull was placed in a plastic box. This setting caused no artifacts in the radiologic image, and CBCT images were also obtained from each tooth.
All intraoral images were exposed with a Minray dental X-ray machine (Soredex, Tuusula, Finland) at $60 \mathrm{kVp}$ and $7.5 \mathrm{~mA}$ with a focus receptor distance at $30 \mathrm{~cm}$. Image receptors at this study were Kodak Insight film (Eastman Kodak Co, Rochester, NY, USA), E Speed, size 2, and two digital sensors: First, digital CCD detector (Sopro Imaging, Ac-t Croup, La Ciotat, France), size 1, pixel size $22 \times 22 \mu \mathrm{m}$ with a resolution of 20 lines/mm and second, PSP detector (Digora optime, Soredex, Tuusula, Finland), size 2, pixel size $35 \mu \mathrm{m}$, bit depth 14.3 lines $/ \mathrm{mm}$.

The CBCT images were obtained with Newtom 3G CBCT (Verona, Italy), gray scale 12 bits, $110 \mathrm{kVp}, 1-15 \mathrm{~mA}$, scan time $18 \mathrm{~s}$, voxel size $0.3 \mathrm{~mm}$, focal spot $0.5 \mathrm{~mm}$.

Exposure time was $0.32 \mathrm{~s}$ for conventional film and 0.10 $\mathrm{s}$ for CCD and PSP. According to the visibility of pulpal root canal, the optimal image quality was determined.

Conventional intraoral films were processed in an automatic processor (HOPE dentamax, Warminster, PA, USA) based on manufacturer's recommendation.

Three calibrated blind observers examined all images for the presence or absence of resorption cavities. The reliability and degrees of agreement were also determined by the mean of Cohen's Kappa analysis. In this study, the values obtained for intra-examiner reliability were above 0.68 with $95 \%$ confidence interval (CI). The Kappa coefficient for inter-examiner was also 0.72 with 95\% CI [Table 2]. Films were evaluated against a light box and digital images were displayed on a 17-inch Samsung monitor (SyncM1aster 740 N, Samsung Co, Korea) with the screen resolution set at $1280 \times 1024$ pixels and color set to 32-bit depth. CBCT images were observed by NNT

Table 1: The distribution of the sample teeth in terms of the cavity location, size, and number

\begin{tabular}{lccc}
\hline Location & $\begin{array}{c}\text { Cervical one-third } \\
\text { of the root }\end{array}$ & $\begin{array}{c}\text { Middle one-third } \\
\text { of the root }\end{array}$ & $\begin{array}{c}\text { Apical one-third } \\
\text { of the root }\end{array}$ \\
\hline Size $(\mathrm{mm})$ & 0.511 .5 & 0.511 .5 & 0.511 .5 \\
Number & 101011 & 1099 & 1099 \\
\hline
\end{tabular}

Table 2: Kappa values and 95\% of confidence interval (CI) for the detection of external root rosorption on the conventional intraoral film radiography, charge-coupled device, photostimulable phosphor plate, and cone beam computed tomography

\begin{tabular}{|c|c|c|c|c|c|c|c|c|}
\hline \multirow[t]{2}{*}{ Observers } & \multicolumn{2}{|r|}{ F } & \multicolumn{2}{|c|}{ CCD } & \multicolumn{2}{|c|}{ PSP } & \multicolumn{2}{|c|}{ СВCT } \\
\hline & K & CI & K & CI & K & CI & K & CI \\
\hline I & 0.68 & $51-0$. & 0.76 & $64-0$. & 0.78 & $68-0.8$ & 0.78 & $70-1.00$ \\
\hline II & 0.72 & $.70-0$ & 0.79 & $62-0$. & 0.84 & $.84-1.0$ & 0.82 & $.72-0.94$ \\
\hline III & 0.87 & $.82-1$. & 0.84 & $.76-1$. & 0.79 & $.79-1.0$ & & $.77-0.96$ \\
\hline
\end{tabular}

Abbreviations: K: Kappa coefficient; CI: Confidence interval to 95\%; CCD: Charge-coupled device; PSP: Photostimulable phosphor plate; CBCT: Cone beam computed tomography 
viewer software and evaluated in axial, sagittal, and coronal views using multiplanar reformation (MPR) option. In this study, ERR cavity assessments were categorized as follows: True positive (sensitivity): Correct detection of ERR cavity site; true negative (specificity): Correct detection of a site without cavity; false positive: Detection of resorption in a site without cavity; and false negative: No detection or false localization of a cavity.

In order to examine these images in more detail, cross-sectional views having slice thickness of $0.5 \mathrm{~mm}$ and $1.0 \mathrm{~mm}$ steps were created; subsequently all root portions were carefully evaluated and any root resorption was recorded in a checklist.

Data were statistically analyzed with the $\chi^{2}$ test to determine differences between the imaging methods to detect ERR. Significance level was considered at $p$ value less than 0.05 .

\section{RESULTS}

The sensitivity, specificity, and accuracy rate of all radiographic imaging methods are summarized in Tables 3 and 4 . Besides, the percentages of false-negative and false-positive evaluation of all imaging methods (film, CCD, PSP, and CBCT) in different cavity sizes and locations are presented in [Tables 3 and 4].

The differences between the imaging methods in correct detection of root resorption for all sizes were not statistically significant $(p>0.05)$.

But for locations of root resorption, significant dif-

Table 3: Sensitivity and specificity of resorption detection according to imaging methods and defect size (in \%)

\begin{tabular}{|c|c|c|c|c|c|c|c|c|c|c|c|c|}
\hline \multirow{2}{*}{$\begin{array}{l}\text { Screening } \\
\text { items }\end{array}$} & \multicolumn{3}{|c|}{$\mathrm{F}$} & \multicolumn{3}{|c|}{$\mathrm{CCD}$} & \multicolumn{3}{|c|}{ PSP } & \multicolumn{3}{|c|}{$\mathrm{CBCT}$} \\
\hline & $0.5 \mathrm{~mm}$ & $1 \mathrm{~mm}$ & $1.5 \mathrm{~mm}$ & $0.5 \mathrm{~mm}$ & $1 \mathrm{~mm}$ & $1.5 \mathrm{~mm}$ & $0.5 \mathrm{~mm}$ & $1 \mathrm{~mm}$ & $1.5 \mathrm{~mm}$ & $0.5 \mathrm{~mm}$ & $1 \mathrm{~mm}$ & $1.5 \mathrm{~mm}$ \\
\hline$n$ & 30 & 28 & 29 & 30 & 28 & 29 & 30 & 28 & 29 & 30 & 28 & 29 \\
\hline Sensitivity & 74 & 80 & 100 & 68 & 87 & 100 & 71 & 87 & 90 & 90 & 90 & 100 \\
\hline Specificity & 96 & 96 & 96 & 86 & 86 & 87 & 92 & 92 & 92 & 94 & 94 & 94 \\
\hline False positive & 4 & 4 & 4 & 14 & 14 & 13 & 8 & 8 & 8 & 6 & 6 & 6 \\
\hline False negative & 26 & 20 & 0 & 32 & 13 & 0 & 29 & 13 & 10 & 10 & 10 & 0 \\
\hline Accuracy rate & 88 & 91 & 97 & 80 & 86 & 91 & 85 & 90 & 91 & 93 & 93 & 96 \\
\hline
\end{tabular}

Abbreviations: F: Conventional radiography film; CCD: Charge-coupled device; PSP: Photostimulable phosphor plate; CBCT: Cone beam computed tomography; n: Cavity number

Table 4: Sensitivity and specificity of resorption detection according to imaging methods and defect location (in \%)

\begin{tabular}{|c|c|c|c|c|c|c|c|c|c|c|c|c|}
\hline \multirow{2}{*}{$\begin{array}{l}\text { Screening } \\
\text { items }\end{array}$} & \multicolumn{3}{|c|}{$\mathrm{F}$} & \multicolumn{3}{|c|}{$\mathrm{CCD}$} & \multicolumn{3}{|c|}{ PSP } & \multicolumn{3}{|c|}{$\mathrm{CBCT}$} \\
\hline & A & M & $\mathrm{C}$ & A & M & $\mathrm{C}$ & A & M & $\mathrm{C}$ & A & M & $\mathrm{C}$ \\
\hline$n$ & 28 & 28 & 31 & 28 & 28 & 31 & 28 & 28 & 31 & 28 & 28 & 31 \\
\hline Sensitivity & 72 & 90 & 90 & 83 & 73 & 97 & 79 & 83 & 84 & 100 & 90 & 90 \\
\hline Specificity & 96 & 100 & 91 & 84 & 96 & 78 & 92 & 96 & 87 & 96 & 100 & 87 \\
\hline False positive & 4 & 0 & 9 & 16 & 4 & 22 & 8 & 4 & 13 & 4 & 0 & 13 \\
\hline False negative & 28 & 10 & 10 & 17 & 27 & 3 & 21 & 17 & 16 & 0 & 10 & 10 \\
\hline Accuracy rate & 88 & 97 & 91 & 84 & 89 & 85 & 88 & 92 & 86 & 97 & 97 & 88 \\
\hline
\end{tabular}

Abbreviations: A: Apical; M: Middle; C: Cervical; F: Conventional radiography film; CCD: Charge-coupled device; PSP: Photostimulable phosphor plate; CBCT: Cone beam computed tomography; $n$ : Cavity number

Table 5: Comparison of correct resorption detection in different cavity size and location between CBCT versus CCD, CBCT versus PSP, CBCT versus F, CCD versus PSP, CCD versus F, and PSP versus F

\begin{tabular}{|c|c|c|c|c|c|c|}
\hline \multirow{3}{*}{$\begin{array}{l}\text { Imaging } \\
\text { methods } \\
n\end{array}$} & \multicolumn{3}{|c|}{ Defect size } & \multicolumn{3}{|c|}{ Defect location } \\
\hline & $0.5 \mathrm{~mm}$ & $1 \mathrm{~mm}$ & $1.5 \mathrm{~mm}$ & Apical & Middle & Cervical \\
\hline & 30 & 28 & 29 & 28 & 28 & 31 \\
\hline CBCT-CCD & 0.05 (n.s.) & 0.69 (n.s.) & 1.00 (n.s.) & $0.05(\mathrm{~S})$ & 0.14 (n.s.) & 0.57 (n.s.) \\
\hline CBCT-PSP & 1.00 (n.s.) & 0.69 (n.s.) & 0.08 (n.s.) & $0.05(\mathrm{~S})$ & 0.51 (n.s.) & 1.00 (n.s.) \\
\hline CBCT-F & 0.10 (n.s.) & 0.28 (n.s.) & 1.00 (n.s.) & $0.05(\mathrm{~S})$ & 0.70 (n.s.) & 0.38 (n.s.) \\
\hline CCD-PSP & 1.00 (n.s.) & 1.00 (n.s.) & 0.08 (n.s.) & 1.00 (n.s.) & 0.40 (n.s.) & 0.57 (n.s.) \\
\hline CCD-F & 0.78 (n.s.) & 0.49 (n.s.) & 1.00 (n.s.) & 1.00 (n.s.) & 0.07 (n.s.) & 0.75 (n.s.) \\
\hline PSP-F & 0.78 (n.s.) & 0.49 (n.s.) & 0.08 (n.s.) & 1.00 (n.s.) & 0.70 (n.s.) & 0.38 (n.s.) \\
\hline
\end{tabular}

Abbreviations: n.s.: Non-significant; S: Significant; F: Conventional radiography film; CCD: Charge-coupled device; PSP: Photostimulable phosphor plate; CBCT: Cone beam computed tomography; $n$ : Cavity number 
ferences were found between $\mathrm{CBCT}$ and other methods for correct detection of root resorption in the apical regions $(p=0.046)$ [Table 5]

On the other hand, there were no significant differences in accuracy rate between imaging methods for all sizes and locations $(p>0.05)$.

\section{DISCUSSION}

Diagnosis of ERR may be challenging, especially when no clinical signs are seen. However, a gold standard for detection of root resorption is still missing. ${ }^{[9,11]}$ In the present study, conventional radiography film, CCD, and CBCT had a $100 \%$ sensitivity to detect large $(1 \mathrm{~mm})$ root resorption cavities. Also, CBCT and CCD had highest and lowest sensitivity in detection of small $(0.5 \mathrm{~mm})$ cavities, respectively $(\mathrm{CBCT}>\mathrm{F}$ $>$ PSP $>$ CCD). Medium cavities were detected with similar rates by PSP and CCD. Higher proportion of correct readings was obtained with CBCT in all resorption sizes.

However, according to Table 4, there were no statistically significant differences between the imaging methods in correct detection of ERR for all sizes. In disagreement with our findings, Chapnick and Kamburo lu et al., showed that the small root resorptive defects were more difficult to identify than larger ones. ${ }^{[1,12]}$

Heo et al., pointed out that small root resorption (as low as $0.5 \mathrm{~mm}$ ) could be detected using digital subtraction radiology. ${ }^{[13]}$ Besides, Borg et al. and Levander et al., showed the performance of digital methods to be equal to that of conventional methods for detecting of ERR cavities. ${ }^{[14,15]}$

In contrast, Westphalen et al. and Kravitz et al., demonstrated that digital radiography was more sensitive than conventional radiography for detection of simulated ERR.$^{\left[{ }^{516]}\right.}$ Also, Andreasen et al. and Goldberg et al., reported that those lesions less than $0.3 \mathrm{~mm}$ in depth and $0.6 \mathrm{~mm}$ in diameter are not detected by conventional periapical radiography. ${ }^{[7,8]}$ Lidke et al., evaluated the diagnostic ability of CBCT for three voxel resolutions in detection of ERR and reported high sensitivity and specificity for all voxel resolutions. ${ }^{[17]}$ Alqerban et al., pointed out that CBCT can be a useful method for evaluation of ERR. ${ }^{[3]}$ The same results were concluded by Dudic et al. and Silveira et al., when they compared CBCT with panoramic radiography. ${ }^{[9,18]}$ In our study, CBCT and CCD had the lowest and the highest percentages of false-negative evaluation of ERR in small defects, respectively $(\mathrm{CBCT}<\mathrm{F}<\mathrm{PSP}<\mathrm{CCD})$.

The percentage of false-negative evaluation of ERR in large cavities was zero for CBCT, CCD, and conventional radiography film.

Conventional radiography film and CCD had the lowest and the highest percentages of false-positive detection of ERR in all cavities sizes, respectively $(\mathrm{F}<\mathrm{CBCT}<\mathrm{PSP}<\mathrm{CCD})$.

In this study, the sensitivity of CBCT in detection of cavities located in the apical one-third of the root was $100 \%$, followed by CCD (83\%), PSP (79\%), and F (72\%). The sensitivity of CBCT and conventional radiography film was equal in detection of simulated ERR defects located in the middle and cervical one-third of the root. According to our findings, CBCT did not have any statistically significant superiority than other imaging methods in cavity detection, except for cavities located in the apical regions. Kamburo lu et al., pointed out that cavities in the apical third were more difficult to detect compared to other cavities. ${ }^{[1]}$ Similar finding was also reported by Dudic et al. ${ }^{[9]}$ In contrast, Andreasen et al., demonstrated that there were no differences in cavity visibility in cervical, middle, or apical regions. ${ }^{[7]}$ In our study, the percentage of false-positive evaluation of root resorption in the middle one-third of the root was zero for conventional intraoral film radiography and CBCT. Also, the percentage of false-negative detection of defects located in the apical regions was zero for CBCT. The percentage values of false-negative evaluation of defects located in the middle and cervical regions were equal for $\mathrm{CBCT}$ and $\mathrm{F}$.

According to our results, CBCT was only useful for detection of cavities located in the apical one-third of the root, compared to other digital or conventional methods. This superiority may be related to these reasons: (1) The ability to assess an area of interest in three dimensions eliminates the superimposition that is inherent in conventional radiographs. (2) In the serial cross-sectional views, the location and the size of root cavity were clear. (3) The ability to reduce superimposition of the surrounding structures makes CBCT superior than conventional image. (4) The sophisticated software of CBCT allows the dentist to select the favorable views for each specific problem being assessed. In intraoral radiographs, the image is steel-distorted because the film and subject are not exactly parallel and the X-ray beam is not directed at right angles to them. This distortion tends to increase along the image toward the apex. ${ }^{[3,19,20]}$ Furthermore, other digital methods (CCD and PSP) did not show any statistically significant superiority than conventional intraoral radiograph in detection of ERR in different sizes and locations.

\section{Conclusion}

CBCT was only useful for detection of cavities located in the apical one-third of the root, compared to other digital or conventional methods.

\section{REFERENCES}

1. Kamburoğlu K, Tsesis I, Kfir A, Kaffe I. Diagnosis of artificially induced external root resorption using conventional intraoral film radiography, CCD, and PSP: An ex vivo study. Oral Surg Oral Med Oral Pathol Oral Radiol Endod 2008;106:885-91. 
2. Ne RF, Witherspoon DE, Gutmann JL. Tooth resorption. Quintessence Int 1999;30:9-25.

3. Patel S, Dawood A, Wilson R, Horner K, Mannocci F. The detection and management of root resorption lesions using intraoral radiography and cone beam computed tomography-an in vivo investigation. Int Endod J 2009;42:831-8.

4. Majorana A, Bardellini E, Conti G, Keller E, Pasini S. Root resorption in dental trauma: 45 cases followed for 5 years. Dent Traumatol 2003;19:262-5.

5. Westphalen VP, Gomes de Moraes I, Westphalen FH, Martins WD, Souza PH. Conventional and digital radiographic methods in the detection of simulated external root resorptions: A comparative study. Dentomaxillofac Radiol 2004;33:233-5.

6. Nance RS, Tyndall D, Levin LG, Trope M. Diagnosis of external root resorption using TACT (tuned-aperture computed tomography). Endod Dent Traumatol 2000;16:24-8.

7. Andreasen FM, Sewerin I, Mandel U, Andreasen JO. Radiographic assessment of simulated root resorption cavities. Endod Dent Traumatol 1987;3:21-7.

8. Goldberg F, De Silvio A, Dreyer C. Radiographic assessment of simulated external root resorption cavities in maxillary incisors. Endod Dent Traumatol 1998;14:133-6.

9. Dudic A, Giannopoulou C, Leuzinger M, Kiliaridis S. Detection of apical root resorption after orthodontic treatment by using panoramic radiography and cone-beam computed tomography of super-high resolution. Detection of apical root resorption after orthodontic treatment by using panoramic radiography and cone-beam computed tomography of super-high resolution. Am J Orthod Dentofacial Orthop 2009;135:434-7.

10. Scarfe WC, Farman AG, Sukovic P. Clinical applications of cone-beam computed tomography in dental practice. J Can Dent Assoc 2006;72:75-80.
11. Patel S, Dawood A. The use of cone beam computed tomography in the management of external cervical resorption lesions. Int Endod J 2007;40:730-7.

12. Chapnick L. External root resorption: An experimental radiographic evaluation. Oral Surg Oral Med Oral Pathol 1989;67:578-82.

13. Heo MS, Lee SS, Lee KH, Choi HM, Choi SC, Park TW. Quantitative analysis of apical root resorption by means of digital subtraction radiography. Oral Surg Oral Med Oral Pathol Oral Radiol Endod 2001;91:369-73

14. Borg E, Källqvist A, Gröndahl K, Gröndahl HG. Film and digital radiography for detection of simulated root resorption cavities. Oral Surg Oral Med Oral Pathol Oral Radiol Endod 1998;86:110-4.

15. Levander E, Bajka R, Malmgren O. Early radiographic diagnosis of apical root resorption during orthodontic treatment: A study of maxillary incisors. Eur J Orthod 1998;20:57-63.

16. Kravitz LH, Tyndall DA, Bagnell CP, Dove SB. Assessment of external root resorption using digital subtraction radiography. J Endod $1992 ; 18: 275-84$

17. Liedke GS, da Silveira HE, da Silveira HL, Dutra V, de Figueiredo JA. Influence of voxel size in the diagnostic ability of cone beam tomography to evaluate simulated external root resorption. J Endod 2009;35:233-5.

18. da Silveira HL, Silveira HE, Liedke GS, Lermen CA, Dos Santos RB, de Figueiredo JA. Diagnostic ability of computed tomography to evaluate external root resorption in vitro. Dentomaxillofac Radiol 2007;36:393-6.

19. Özer SY. Diagnosis and treatment modalities of internal and external cervical root resorption: Review of the literature with case reports. J Dent Res 2011;1:32-7.

20. White SC, Pharoah MJ. Text book oral radiology principles and interpretation, $5^{\text {th }}$ ed. St. Louis: Mosby; 2004. 